\title{
PREVENTION AND MANAGEMENT OF WORK-RELATED CARDIOVASCULAR DISORDERS
}

\author{
AKIZUMI TSUTSUMI \\ Kitasato University School of Medicine, Sagamihara, Japan \\ Department of Public Health
}

\begin{abstract}
Cardiovascular disorders (CVDs) constitute a major burden for health of working populations throughout the world with as much as $50 \%$ of all causes of death and at least $25 \%$ of work disability. There are some changes in CVD risk factors among occupational classes. This is mainly due to the new types of work-related causes of morbidity associated with the recent developments in global work life, particularly in the industrialized countries. Meanwhile, in the developing countries or those in transition (e.g., in Eastern Europe), CVD mortality is increasing due to major socioeconomic changes, the demographic transition and rapid industrialisation and urbanisation, all leading to growing challenges to cardiovascular health. Better control of known risk factors (i.e., smoking, obesity, physical inactivity, high cholesterol, high blood pressure, and high blood glucose) is effective to prevent CVD incidence. But the expected improvement has not been achieved. The obstacles of achieving such impact are due to lack of awareness, lack of policies and their implementation into practice and shortage of infrastructures and human resources. These are needed for wide-scale and long-term programme implementation. Considering the WHO Global Strategy on Occupational Health for All, the WHO Global Action Plan on Workers' Health, the WHO Programme on Prevention of Non-communicable Diseases and the ILO Decent Work agenda, the 6th ICOH International Conference on Work Environment and Cardiovascular Diseases adopted the Tokyo Declaration.
\end{abstract}

Key words:

Cardiovascular disorders, Policy, Prevention, Stress, Training, Work-related

\section{INTRODUCTION}

Cardiovascular disorders (CVDs) constitute a major burden for health of working populations throughout the world [1] with as much as $50 \%$ of all causes of death and at least $25 \%$ of work disability. According to research data, about 10 to $20 \%$ of all causes of CVD deaths among the working age populations can be attributed to work, i.e., are work-related. The loss of work days and work ability is likely to be substantially greater.

While CVD mortality is declining in developed countries, trends in incidence and prevalence are not parallel across age- and gender-groups, geographical areas, and sectors of the economy or among certain occupational groups [2]. In industrialized countries, while CVD mortality and myocardial infarction incidence are decreasing, some data indicate that if the acute coronary syndrome are included in the endpoint, the trends get flat, having as a net effect the increase in prevalence of the chronic forms of the disease, with its consequences in terms of returns to work.

Also there are some changes in CVD incidence among occupational classes. This is mainly due to the new types of work-related causes of morbidity associated with the

This manuscript was based on the Tokyo declaration adopted by the Plenary of the 6th ICOH International Conference on Work Environment and Cardiovascular Diseases (2013 Mar 27-30; Tokyo, Japan) under the auspices of the ICOH Scientific Committee on Cardiology in Occupational Health in Tokyo, and presented at the Nofer Institute of Occupational Medicine 60th Anniversary Celebration Week: The Occupational Medicine Days International Workshop "Healthy lifestyles and ageing at work." Received: August 21, 2014. Accepted: August 28, 2014.

Corresponding author: A. Tsutsumi, Kitasato University School of Medicine, Department of Public Health, 1-15-1 Kitasato, Minami, Sagamihara, Kanagawa, 252-0374, Japan (e-mail: akizumi@kitasato-u.ac.jp). 
recent developments in global work life, particularly in the industrialized countries, which give rise to psychosocial and physical risk factors in the work environment such as growing competition and time pressures, productivity pressures, continuous organisational changes, re-engineering and downsizing, lean production, job insecurity and threat of unemployment, introduction of new technologies and increase of sedentary work, changing patterns of working hours and partially extensive working hours. Meanwhile, in the developing countries or those in transition (e.g., Eastern Europe), CVD mortality is increasing due to major socioeconomic changes, the demographic transition and rapid industrialisation and urbanisation all leading to growing challenges to cardiovascular health.

Ageing of working populations and life style risk factors such as low-level physical activity during leisure time enhance the risk of CVDs and are often in complex interaction with the work-related factors. For example, certain working conditions may be important determinants of obesity, due to sedentary labour and promotion of unhealthy behaviours at work (e.g., stress-related eating) and through them, determinants of workers' cardiovascular health as well.

Available research data suggest that about $80 \%$ of CVD mortality is preventable if the existing knowledge could be effectively used for system-wide implementation of prevention and health promotion programmes. Some countries have shown convincing examples of such system-wide impact.

The obstacles of achieving such wide-scale impact are less due to lack of knowledge or standardised methods than to lack of awareness, lack of policies and their implementation into practice and shortage of infrastructures and human resources needed for wide-scale and long-term programme implementation.

Considering the WHO Global Strategy on Occupational Health for All, the WHO Global Action Plan on Workers' Health, the WHO Programme on Prevention of Noncommunicable Diseases and the ILO Decent Work agenda, the 171 participants of the 6th ICOH International
Conference on Work Environment and Cardiovascular Diseases, coming from 28 countries, agreed to declare the following.

\section{THE TOKYO DECLARATION ON PREVENTION AND MANAGEMENT OF WORK-RELATED CARDIOVASCULAR DISORDERS \\ Burden of CVD}

Working peoples throughout the world are heavily burdened by CVD in general and work-related cardiovascular disorders in particular leading to loss of health, productive working years, work ability, quality of life years and of economic values [1].

\section{CVD is preventable}

A major part of workers' cardiovascular disorders is preventable on the basis of available research evidence and knowledge [3]. Such prevention needs long-term strategies and programmes and support from all levels of the system, starting from the policy level and extending to the level of the health sector and company management, academia, occupational health practitioners, workers and employers.

\section{Prevention programs}

As risk factors for cardiovascular morbidity of workers develop from many sources; including non-modifiable genetic and age-related factors, occupational factors, lifestyle and behavioural factors and social determinants, therefore prevention strategies need to be designed to target these multiple factors in the context of comprehensive multidisciplinary programmes [4].

\section{System-wide prevention needed}

Effective prevention of work-related cardiovascular disorders needs a system-wide approach utilizing as much as possible existing and permanent infrastructures covering the whole working population and serving particularly those most in need, especially small-scale and micro enterprises, self-employed, rural workers and those workers in the 
informal sector. It is the public sector responsibility to ensure that such services be made available for all workers [5].

\section{Future research needs}

In addition to implementing existing research, new research efforts are needed to identify and assess emerging and developing risks related to the rapid changes of modern work life also affecting cardiovascular health of workers, such as continuous work overload, low control especially with high demand, low reward for high effort, job insecurity, lean work systems, sedentary work and their health consequences and operating mechanisms [6]. Development of new indicators for assessment of new complex exposures and their health effects is warranted. More research is also needed on implementation of research knowledge into work life practice, health services research on occupational health services, including evaluation of impact from policies and practices.

\section{High risk workers}

Work-related cardiovascular disorders among workers of developing countries, small enterprises, agricultural workers and workers in the informal sector require special research efforts in order to measure the dimensions of morbidity and its impact on the populations of concern [7].

\section{Public database needed}

Data and information systems, including those related to cardiovascular health should be made available for research purposes where appropriate. Long-term sustainability of such registries should be ensured. Multisectoral and international collaboration and linkages of such data should be enabled and encouraged within the limits of the ethical principles and regulations regarding protection of confidential personal data.

\section{Training in occupational risk for CVD}

Health sector practitioners, including general practitioners, clinicians, occupational health experts, as well as researchers, should be given more training on the work-related character of cardiovascular disorders and their impact on the health and work ability of working populations, work life in general and on their economic dimensions. Training of sufficient human resources for occupational health services needed for implementation of research knowledge into practice is encouraged.

\section{Need for evidence-based prevention and treatment guidelines}

Evidence-based and feasible methods, guidelines and good practices should be developed for use in occupational health services and at the grassroots level for prevention and management of work-related cardiovascular disorders and other newly recognized health outcomes among workers. This will require a more rigorous research methodology, including registration of workplace interventions, to assess their effectiveness.

\section{Commitment of ICOH Scientific Committee on Cardiology in Occupational Health}

The ICOH 2013 Conference through the ICOH Scientific Committee on Cardiology in Occupational Health is committed to continue research and related efforts for identification, assessment and prevention of work-related cardiovascular disorders. Likewise, our commitment will involve collaboration with other relevant ICOH Scientific Committees and other partners who may work in the field of work and cardiovascular health.

\section{ACKNOWLEDGMENTS}

The members of the ICOH Scientific Committee on Cardiology in Occupational Health, Jian Li (secretary), Hynek Pikhart (vice chair), Peter Schnall, Peter Smith, (Scientific Advisory Committee), Alicja Bortkiewicz, Elżbieta Gadzicka, Paul Landsbergis, Els Clays, Marco Ferrario, BongKyoo Choi, Uche Ojomo, are appreciated very much for their support. Professors Jorma Rantannen, Mika Kivimaki and Töres Theorell are also acknowledged for their substantial contribution to the Tokyo declaration. 


\section{REFERENCES}

1. Alwan A; World Health Organization. Global status report on noncommunicable diseases 2010. Geneva: WHO Press; 2011.

2. Mirzaei M, Truswell AS, Taylor R, Leeder SR. Coronary heart disease epidemics: Not all the same. Heart. 2009;95(9):740-6, http://dx.doi.org/10.1136/hrt.2008.154856.

3. di Chiara A, Vanuzzo D. Does surveillance impact on cardiovascular prevention? Eur Heart J. 2009;30(9):1027-9, http:// dx.doi.org/10.1093/eurheartj/ehp025.

4. Watt RG. Strategies and approaches in oral disease prevention and health promotion. Bull World Health Org. 2005;83(9):711-8.

5. Weintraub WS, Daniels SR, Burke LE, Franklin BA, Goff DC Jr., Hayman LL, et al. Value of primordial and primary prevention for cardiovascular disease: A policy statement from the American Heart Association. Circulation. 2011;124 (8):967-90, http://dx.doi.org/10.1161/CIR.0b013e3182285a81.

6. Perk J, de Backer G, Gohlke H, Graham I, Reiner Z, Verschuren WM, et al. European guidelines on cardiovascular disease prevention in clinical practice (version 2012): The fifth joint task force of the European Society of Cardiology and other societies on cardiovascular disease prevention in clinical practice (constituted by representatives of nine societies and by invited experts). Int J Behav Med. 2012;19(4):403-88, http://dx.doi.org/10.1007/s12529-012-9242-5.

7. Carnethon M, Whitsel LP, Franklin BA, Kris-Etherton P, Milani R, PrattCA, et al. Worksite wellness programs for cardiovascular disease prevention: A policy statement from the American Heart Association. Circulation. 2009;120(17):1725-41, http://dx.doi.org/10.1161/CIRCULATIONAHA.109.192653.

This work is available in Open Access model and licensed under a Creative Commons Attribution-NonCommercial 3.0 Poland License - http://creativecommons.org/ licenses/by-nc/3.0/pl/deed.en. 